\title{
SILÍCIO COMO INDUTOR DE RESISTÊNCIA NO CONTROLE DO TRIPES DO PRATEAMENTO Enneothrips flavens MOULTON, 1941 (THYSANOPTERA: THRIPIDAE) E SEUS REFLEXOS NA PRODUTIVIDADE DO AMENDOINZEIRO ${ }^{1}$
}

\author{
Silicon as a resistance inducer controlling the silvering thrips Enneothrips flavens \\ Moulton, 1941 (Thysanoptera: Thripidae) and its effects on peanut yield ${ }^{1}$ \\ Cleiton Dalastra' ${ }^{2}$, Alcebiades Ribeiro Campos $^{3}$, Francisco Maximino Fernandes ${ }^{3}$, \\ Gustavo Luís Mamoré Martins ${ }^{4}$, Zeneide Ribeiro Campos ${ }^{5}$
}

\begin{abstract}
RESUMO
O tripes do prateamento, Enneothrips flavens Moulton, 1941, é considerado a principal praga do amendoim no Brasil, por sua ocorrência generalizada, pelos elevados níveis populacionais e pelos danos causados a cultura. Objetivou-se, com este trabalho, avaliar o efeito do silício sobre a população de E. flavens e sobre a produtividade do amendoinzeiro. Avaliaram-se, semanalmente, 10 folíolos abertos ou semi-abertos no terço superior das plantas do cultivar IAC 886, por parcela. Os tratamentos foram constituídos por: uma aplicação foliar de silício realizada aos 20 dias após a emergência, duas aplicações foliares de silício realizadas aos 20 e 55 dias, e o controle. Uma aplicação de silício proporcionou proteção às plantas de amendoim, reduzindo o número de adultos e ninfas do tripes de E. flavens e aumentou a produtividade da cultura em 31,30\% de amendoim em casca e 28,85\% em grãos.
\end{abstract}

Termos para indexação: Proteção de plantas, resistência induzida, táticas alternativas, amendoim.

\section{ABSTRACT}

The silvering thrips, Enneothrips flavens Moulton, 1941 is considered the major pest on peanuts in Brazil, due to its widespread occurrence, high population levels, and high damage to the crop. The objective of this study was to evaluate the effect of silicon on E. flavens populations and on peanuts yield. Ten fully-opened or semi-opened leaflets per plant were sampled weekly from the peanut cultivar IAC 886. The following treatments were tested: leaf spraying of silicon at 20 days after plant emergence, two leaf spraying of silicon at 20 and 55 days, and the control check. A single silicon spraying provided protection to peanut by reducing the number of E. flavens adults and nymphs and by increasing the yield of peanut pods by $31.30 \%$ and peanut grains by $28.85 \%$.

Index terms: Plant protection, induced resistance, alternative tactics, peanut.

(Recebido em 1 de fevereiro de 2010 e aprovado em 11 de novembro de 2010)

\section{INTRODUÇÃO}

No Brasil, a espécie Enneothrips flavens Moulton, 1941 causa o prateamento das folhas do amendoinzeiro, sendo a praga de maior incidência e importância nessa cultura (Lasca et al., 1990). Geralmente, ataca as plantas durante todo seu desenvolvimento, com maiores danos durante o período de enchimento de grãos (Freddi et al., 2007). Os inseticidas são a principal forma de controle de E. flavens na cultura do amendoim, sendo realizadas de 3 a 5 aplicações durante o ciclo da cultura (Lasca et al., 1990). Esses inseticidas nem sempre apresentam a eficiência desejada, requerendo, com frequência, maior número de aplicações e doses mais elevadas, ocasionando assim, maiores danos ao ambiente e à saúde do homem (Moraes et al., 1997).

Em consequência dos efeitos indesejáveis causados pelos inseticidas aos sistemas agrícolas por ocasião do manejo fitossanitário (Chaboussou, 1999), novas táticas de controle vêm sendo estudadas (Freddi et al., 2007). Dentro desse aspecto, o uso do silício representa uma tecnologia ambientalmente correta, sustentável, com grande potencial para diminuir a frequência e o uso de inseticidas (Lima Filho, 2010; Silva et al, 2010). O silício, apesar de atuar como elemento de defesa na planta (Korndorfer \& Datnoff, 1995; Pereira Junior et al, 2010), é considerado um micronutriente (Brasil, 2004), podendo elevar a produtividade de algumas plantas, principalmente

²Estadual Paulista "Júlio de Mesquita Filho"/UNESP - Avenida Brasil - 56 - Centro - 15385-000 - Ilha Solteira, SP - sauems@gmail.com "Universidade Estadual Paulista "Júlio de Mesquita Filho"/UNESP - Departamento de Fitossanidade, Engenharia Rural e Solos - Ilha Solteira, SP "Universidade Estadual Paulista "Júlio de Mesquita Filho" - Ilha Solteira, SP

5Universidade Estadual Paulista "Júlio de Mesquita Filho" - Departamento de Biologia e Zootecnia - Ilha Solteira, SP 
gramíneas, por meio de uma nutrição equilibrada e fisiologicamente mais eficiente (Korndorfer \& Datnoff, 1995), pois as plantas se apresentam vigorosas e resistentes às pragas e doenças (Lima Filho, 2010).

$\mathrm{O}$ silício pode proporcionar efeitos benéficos às plantas, como resistência a insetos e ao desenvolvimento e penetração de fungos nos tecidos (Marschner, 1995; Epstein, 2001). A proteção conferida às plantas pelo silício pode ser devida ao acúmulo e polimerização de silicatados (sílica amorfa) nas células epidérmicas, abaixo da cutícula, formando uma barreira mecânica conhecida como dupla camada silíciocutícula (Yoshida et al., 1962; Goussain et al., 2002).

A presença do silício na epiderme dificulta a penetração de estiletes e a mastigação pelos insetos, em decorrência do endurecimento da parede das células vegetais (Datnoff et al., 1991; Epstein, 1994; Marschner, 1995) e/ou pela sua ação como ativador nos processos de resistência induzida (Fawe et al., 2001; Gomes et al., 2005). $\mathrm{O}$ silício exerce influência nas respostas bioquímicas da planta e na síntese de toxinas que atuarão como substâncias inibidoras ou repelentes na planta (Marschner, 1988; Epstein, 1994; Dannon \& Wydra, 2004).

Os efeitos do silício no controle de insetos são os mais distintos, como maior desgaste na região incisora das mandíbulas, mortalidade e canibalismo de lagartas de Spodoptera frugiperda J.E. Smith, 1797 ao final do segundo instar (Goussain et al., 2002); redução no número ninfas da cigarrinha Sogatella furcifera Horváth, 1899 que atingiram a fase adulta em plântulas de arroz tratadas com silício (Kim \& Heinrichs, 1982); aumento da resistência de plantas de sorgo ao pulgão Schizaphis graminum Rondani, 1852 (Costa \& Moraes, 2002); e menor preferência de $S$. graminum por plantas de trigo, conferindo a elas uma resistência moderada (Basagli et al., 2003).

Para induzir o aumento da resistência das plantas por meio do silício, são alocados recursos para a síntese de compostos de defesa. Em decorrência disso, é importante avaliar os efeitos do silício sobre possíveis perdas (Délano-Frier et al., 2004) ou ganhos de produtividade (Nojosa et al., 2006). A presença de altos níveis de silício na planta altera o comportamento e reduz ou cessa a alimentação dos insetos (Savant et al., 1997), constituindo-se em uma tática alternativa de controle. Assim, neste trabalho, o objetivo foi avaliar o efeito do silício como indutor de resistência ao tripes do prateamento E. flavens Moulton, 1941 e seus reflexos na produtividade do amendoinzeiro.

\section{MATERIAL E MÉTODOS}

O experimento foi desenvolvido na chácara Esperança, localizada no município de Cassilândia-MS, coordenadas $19^{\circ} 06^{\prime} 48^{\prime \prime} \mathrm{S} ; 51^{\circ} 44^{\prime} 03^{\prime \prime} \mathrm{W}$ e $470 \mathrm{~m}$ de altitude. A chácara possui uma área aproximada de sete hectares, com vegetação pré-existente caracterizada como floresta semi-decídua, inserida em uma formação vegetal do tipo Savana Arbórea Densa (Cerradão) tendendo a Savana Arbórea Aberta (Cerrado), com solo classificado como Latossolo vermelho distrófico (Empresa Brasileira de Pesquisa Agropecuária - Embrapa, 1999).

Com base nos resultados da análise do solo (Tabela 1), foram realizadas duas aplicações de calcário dolomítico $(\mathrm{PRNT}=80 \%)$ na dose de duas toneladas por hectare cada uma, espaçadas de 30 dias e o produto foi incorporado ao solo por meio de gradagem, ambas realizadas com grade aradora. A correção do solo atende às recomendações de Raij et al. (1996) de forma a elevar a saturação de bases a $70 \%$.

Para o desenvolvimento do experimento utilizouse o delineamento inteiramente casualisado com oito repetições e tratamentos constituídos por variações no número de aplicações foliares de silício na dose de $150 \mathrm{~g} \mathrm{ha}^{-1} \mathrm{de} \mathrm{SiO}_{2}$, na forma de Supa Sílica ${ }^{\circledR}(10 \%$ de $\mathrm{SiO}_{2}$ ), aplicado em 2001 calda ha-1. Os tratamentos foram constituídos por uma aplicação foliar de silício realizada aos 20 dias após a emergência (DAE), duas aplicações foliares de silício realizadas aos 20 e 55 dias e controle. Cada parcela constou de 4 linhas de $4 \mathrm{~m}$ de comprimento, espaçadas de $0,9 \mathrm{~m}$.

Na semeadura, realizada em 06 de dezembro de 2007, utilizou-se o cultivar IAC 886 de hábito de crescimento rasteiro. $\mathrm{Na}$ adubação de semeadura, foram aplicados $80 \mathrm{~kg} \mathrm{ha}^{-1}$ de $\mathrm{P}_{2} \mathrm{O}_{5}$ e $14 \mathrm{~kg} \mathrm{ha}^{-1}$ de $\mathrm{K}_{2} \mathrm{O}$. Foram feitas duas aplicações em cobertura, aos 12 e 33 dias após a emergência, com $13 \mathrm{~kg} \mathrm{ha}^{-1}$ de $\mathrm{K}_{2} \mathrm{O}$, conforme recomendação de Raij et al. (1996).

Tabela 1 - Analise química do solo da área experimental.

\begin{tabular}{cccccccccc}
\hline $\mathrm{pH} \mathrm{CaCl}_{2}$ & $\mathrm{MO}$ & $\begin{array}{r}\mathrm{P}-\text { resina } \\
\end{array}$ & $\mathrm{K}$ & $\mathrm{Ca}^{2+}$ & $\mathrm{Mg}^{2+}$ & $\mathrm{H}+\mathrm{Al}$ & $\mathrm{SB}$ & $\mathrm{CTC}$ & $\begin{array}{c}\mathrm{V} \\
\mathrm{mmol}_{\mathrm{c}} \mathrm{dm}^{-3}\end{array}$ \\
\hline 4,2 & 10 & 5 & 1 & 1 & 1 & 47 & 3 & 50 & 6 \\
\hline
\end{tabular}


Com relação ao controle de plantas daninhas, foram realizadas uma capina manual após a emergência e duas aplicações do herbicida haloxifope-R na dose de $60 \mathrm{~g}$ i.a ha ${ }^{-1}$ aos 46 e 96 dias. Foram feitas aplicações do fungicida tebuconazole na dose de 100 g i.a ha-1, aos 103 e 110 dias, para controle da pinta-preta Cercosporidium personatum (Berk. \& Curt.).

As amostragens foram realizadas semanalmente a partir de 16 dias após emergência das plantas, no total de 12 amostragens. Em cada amostragem, foram coletados, ao acaso, 10 folíolos abertos ou semiabertos no terço superior das plantas por parcela. Após coletados, os folíolos foram colocados em sacos plásticos previamente etiquetados, acondicionados em caixa de isopor e transportados para o laboratório de Entomologia Agrícola FE/UNESP. Um microscópio estereoscópico foi utilizado para realização das contagens de adultos e ninfas de E. flavens presentes nos folíolos.

No final do ciclo da cultura, quando as vagens atingiram o ponto de maturação fisiológica, foi realizada colheita manual, no dia 07 de maio de 2008. Para avaliação dos componentes de produção, foram considerados: produtividade de amendoim em casca e grãos, massa de 100 grãos, número de grãos por vagem e rendimento, caracterizado pela relação entre a produção de amendoim em grão e amendoim em casca.

Os dados referentes a números de tripes, previamente transformados em $(\mathrm{x}+0,5)^{1 / 2}$, foram submetidos à análise de variância pelo teste $\mathrm{F}$ e as médias comparadas pelo teste de Tukey a $5 \%$ de probabilidade.

\section{RESULTADOS E DISCUSSÃO}

O número de adultos de E. flavens em cultura de amendoim apresentou diferença significativa entre os tratamentos nas amostragens realizadas no período de 51 a 86 dias após emergência (Figura 1). Em função das concentrações de silício aplicadas, no período de 30 a 51 dias, o número de adultos entre os tratamentos foi semelhante quando comparado ao controle. Entre 51 e 86 dias, observou-se uma maior redução do número de adultos entre os tratamentos e controle, enquanto o efeito de uma segunda aplicação de silício no controle do tripes foi insignificante, possivelmente devido ao pouco tempo entre a aplicação e a amostragem.

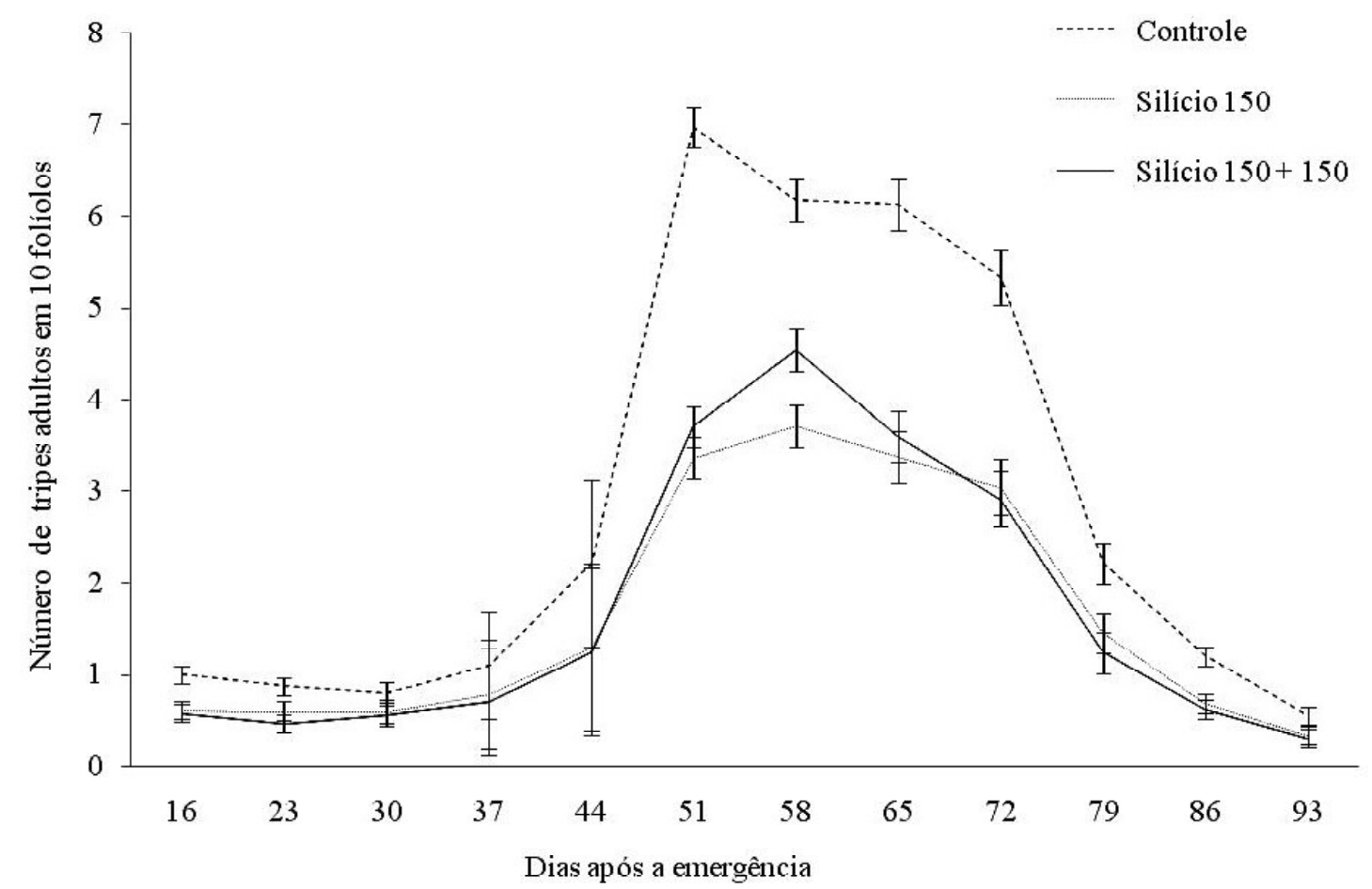

Figura 1 - Número de adultos de tripes do prateamento Enneothrips flavens Moulton, 1941 por 10 folíolos sob efeito de aplicações de silício em amendoinzeiro, cultivar IAC-886 (pontos com barras sobrepostas não diferem pelo teste de Tukey a 5\%). Cassilândia, MS, 2007. 
Diferenças entre os números totais de adultos de E. flavens foram observadas para os tratamentos testados em relação a testemunha (Figura 2). Quando se compara o efeito do silício em uma e duas aplicações, observam-se reduções no número de adultos da ordem de $40 \%$. Nenhum efeito significativo na redução do número de adultos foi observado quando foram realizadas duas aplicações de silício aos 55 DAE.
Comparando-se os números de ninfas de E. flavens, observaram-se diferenças significativas entre os tratamentos avaliados para a maioria das amostragens realizadas no período de 37 a 72 dias após emergências das plantas (Figura 3). No período de 37 a 51 dias, a redução no número de ninfas variou de 35 a 54\%, independente do tratamento, relativamente ao controle. Quando se considera o período de 51 a 72 dias, a

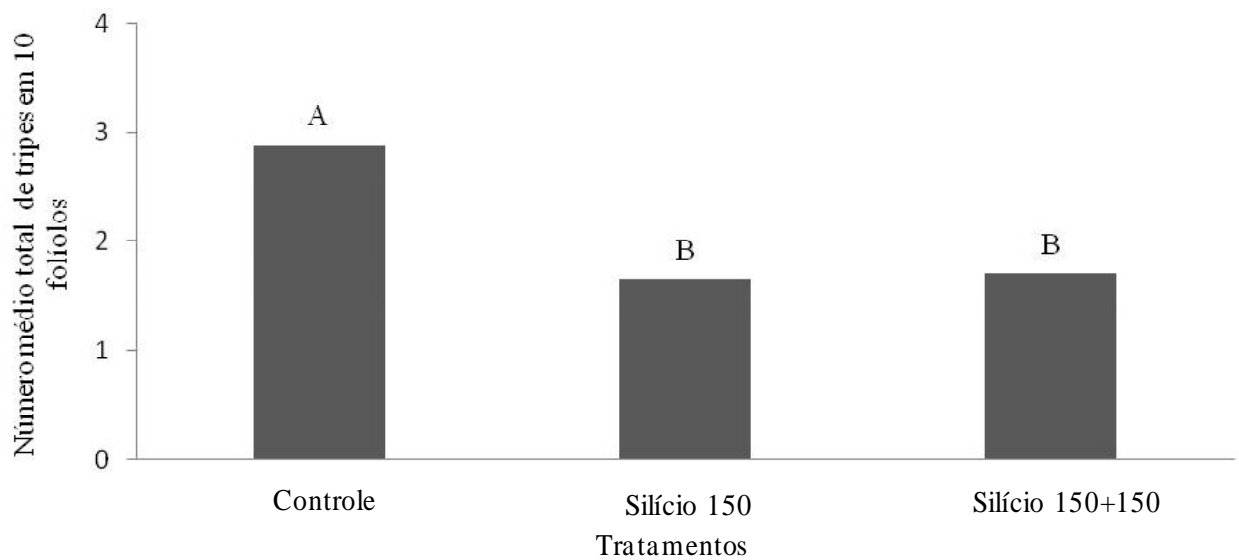

Figura 2 - Número total médio de adultos de tripes do prateamento Enneothrips flavens Moulton, 1941 por 10 folíolos sob efeito de aplicações de silício em amendoinzeiro, cultivar IAC-886. Cassilândia, MS, 2007.

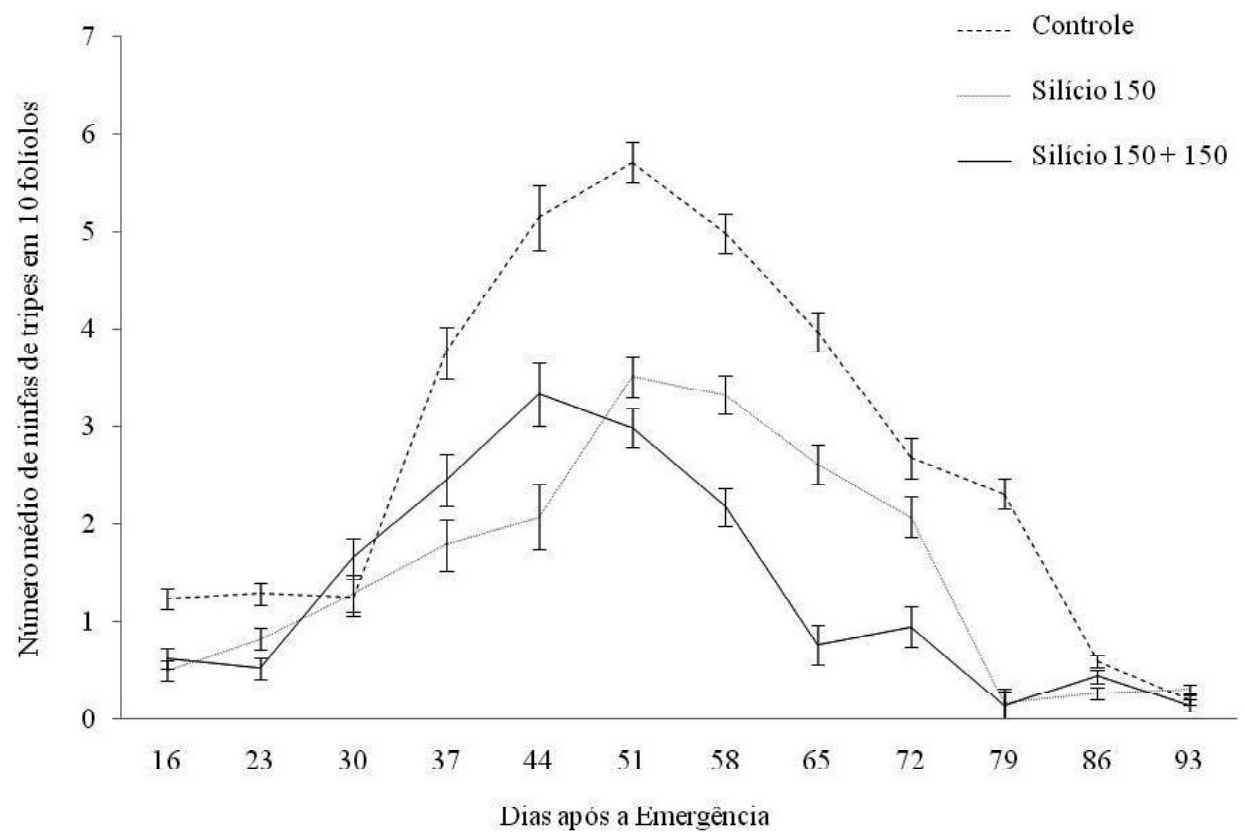

Figura 3 - Número de ninfas de tripes do prateamento Enneothrips flavens Moulton, 1941 por 10 folíolos sob efeito de aplicações de silício em amendoinzeiro, cultivar IAC-886 (pontos com barras sobrepostas não diferem pelo teste de Tukey a 5\%). Cassilândia, MS, 2007. 
redução do número de ninfas foi de 37 a $57 \%$, sempre a favor das plantas protegidas com duas aplicações de silício.

Com relação ao número total de ninfas de $E$. flavens, diferenças significativas foram observadas entre os tratamentos, embora o efeito das aplicações de silício sobre esta fase da praga seja semelhante (Figura 4). Para uma aplicação do silício, ocorreu uma redução do número de ninfas da ordem de $43 \%$, enquanto, para duas aplicações, esta foi de aproximadamente 51\%. Costa et al. (2007) observaram uma redução de $89,3 \%$ na população do pulgão $S$. graminum pela aplicação de silício na dose de $0,5 \%$ em duas aplicações aos 20 e aos 30 dias após emergências de plantas de sorgo.

Foram encontradas diferenças significativas entre tratamentos e controle para os números de adultos e ninfas de E. flavens no período de 37 a 86 dias após a emergência das plantas (Figura 5). O efeito do silício sobre o número de tripes ficou evidente 19 dias após a primeira aplicação,

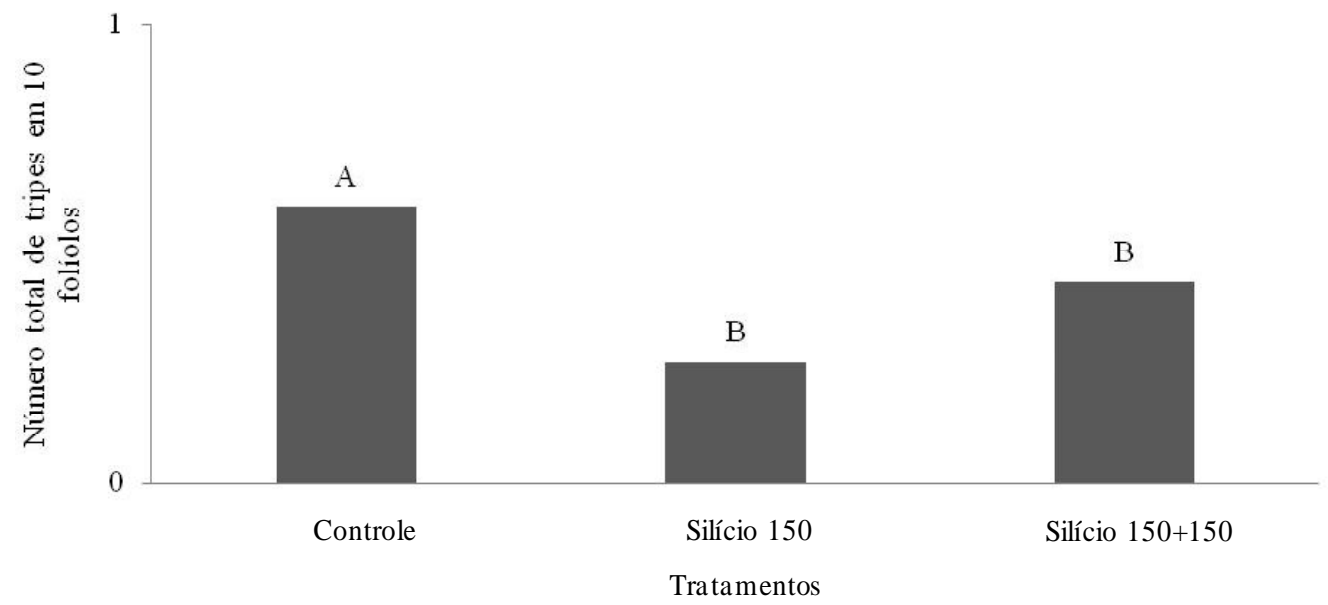

Figura 4 - Número total médio de ninfas de tripes do prateamento Enneothrips flavens Moulton, 1941 por 10 folíolos sob efeito de aplicações de silício em amendoinzeiro, cultivar IAC 886. Cassilândia, MS, 2007.

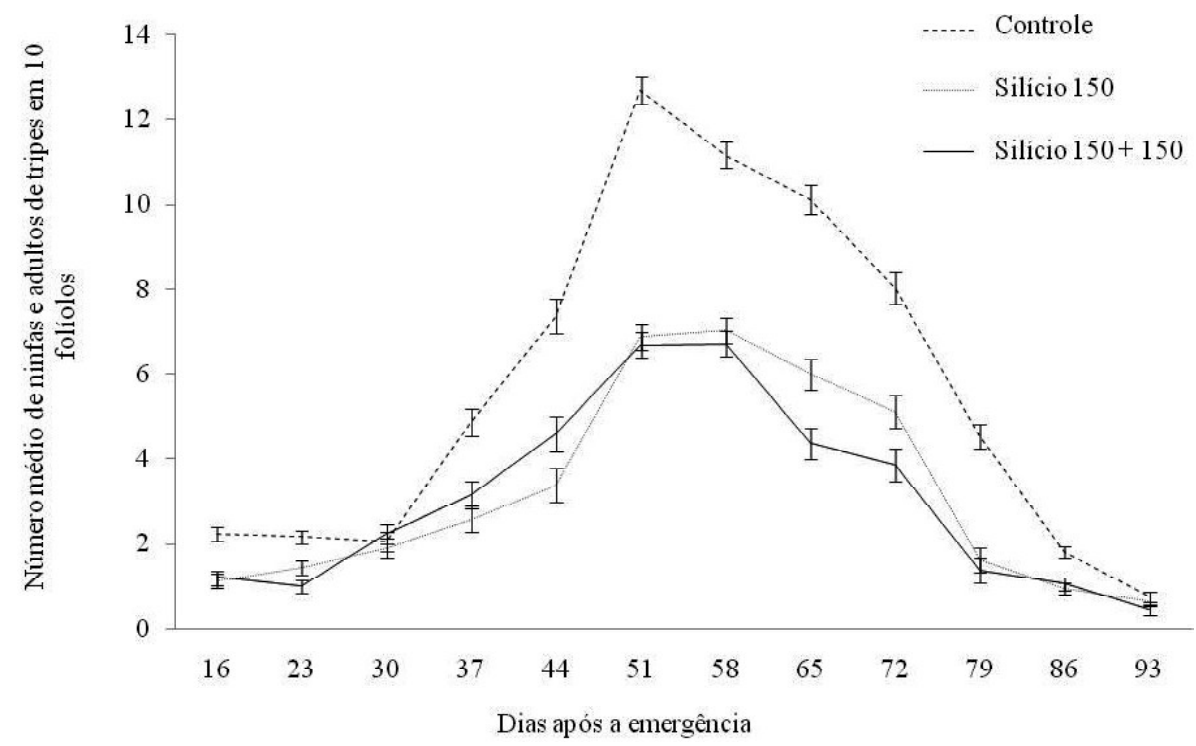

Figura 5 - Número de adultos e ninfas de tripes do prateamento Enneothrips flavens Moulton, 1941 por 10 folíolos sob efeito de aplicações de silício em amendoinzeiro, cultivar IAC-886 886 (pontos com barras sobrepostas não diferem pelo teste de Tukey a 5\%). Cassilândia, MS, 2007. 
quando ocorreram reduções significativas da ordem de $47 \%$. Para o período de 37 a 86 dias, a redução do número de adultos e ninfas variou de 35 a $70 \%$ entre plantas tratadas com uma e duas aplicações de silício e o controle. Quando foram comparados os números de adultos e ninfas entre os tratamentos a base de silício, observaram-se diferenças pequenas, semelhantes, ora em favor da menor dose, ora da maior, mas nunca superior a 36\%. De maneira semelhante, Moraes et al. (2004) verificaram que a aplicação de silício aumentou o grau de resistência das plantas de trigo ao pulgão S. graminum Rondani, 1852, diminuindo a preferência do pulgão-verde em relação à testemunha.

Os números totais de adultos e ninfas de $E$. flavens em plantas de amendoim foram diferentes significativamente entre os tratamentos avaliados (Figura 6). Para uma aplicação de silício, observou-se uma redução do número de adultos e ninfas de aproximadamente $43 \%$ e, para duas aplicações, a redução foi de $51 \%$. Segundo Subramanian \& Gopalaswamy (1988) o uso de silício causou uma redução na população do tripes Stenchaetothrips biformis Bagnall 1913 em plantas de arroz.

As densidades de adultos, ninfas e adultos mais ninfas de E. flavens foram adequadas para avaliar o efeito de aplicações de silício em cultura de amendoim, com hábito de crescimento rasteiro, em condições de campo (Figuras 2, 4 e 6). Baixa densidade de adultos de E. flavens em cultura de amendoim, em condições de campo, segundo Gabriel et al. (1999) foram inadequadas para avaliar os efeitos de genótipos em relação a infestação de E. flavens.

Os dados de produtividade de amendoim em casca $\left(\mathrm{kg} \mathrm{ha}^{-1}\right)$ e grãos $\left(\mathrm{kg} \mathrm{ha}^{-1}\right)$ colhidos em plantas de amendoim tratadas com uma e duas aplicações de silício nas doses em relação ao controle foram diferentes significativamente (Tabela 2). Plantas tratadas com uma aplicação de silício deixaram de perder $31,3 \%$ de amendoim em casca e $28,85 \%$ em grãos, enquanto, para duas aplicações de silício, esses componentes não apresentaram diferença em relação ao tratamento anterior.
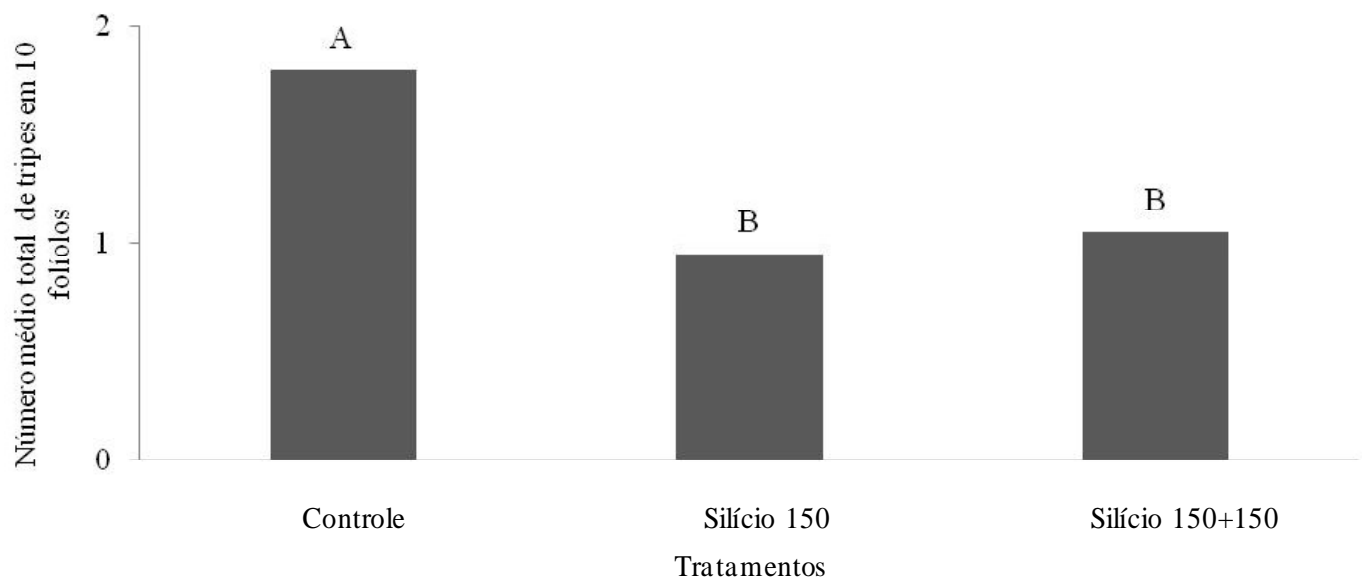

Figura 6 - Número total médio de ninfas de tripes do prateamento Enneothrips flavens Moulton, 1941 por 10 folíolos sob efeito de aplicações de silício em amendoinzeiro, cultivar IAC 886. Cassilândia, MS, 2007.

Tabela 2 - Produtividade média de amendoim em casca $\left(\mathrm{kg} \mathrm{ha}^{-1}\right)$, em grãos ( $\left.\mathrm{kg} \mathrm{ha}^{-1}\right)$, massa de 100 grãos (g), grãos por vagem e rendimento em função de aplicações de silício. Cassilândia-MS, 2007/2008.

\begin{tabular}{|c|c|c|c|c|c|}
\hline \multirow{2}{*}{ Tratamentos } & \multicolumn{2}{|c|}{ Produtividade } & \multirow{2}{*}{ Massa de 100 grãos (g) } & \multirow{2}{*}{$\mathrm{N}^{\mathrm{o}}$ grãos por vagem } & \multirow{2}{*}{ Rendimento $(\%)$} \\
\hline & Grãos & Casca & & & \\
\hline Silício150 & $3291,98 a^{(1)}$ & $4675,34 \mathrm{a}$ & $58,94 \mathrm{a}$ & $1,97 \mathrm{a}$ & 70 \\
\hline Silício $150+150$ & $3272,87 \mathrm{a}$ & $4721,34 \mathrm{a}$ & $59,00 \mathrm{a}$ & $1,96 \mathrm{a}$ & 69 \\
\hline Controle & $2261,35 \mathrm{~b}$ & $3326,53 \mathrm{~b}$ & $56,89 \mathrm{~b}$ & $1,93 \mathrm{a}$ & 74 \\
\hline F (Trat.) & $42,28^{*}$ & $14,35^{*}$ & $25,79 *$ & $0,97 \mathrm{~ns}$ & - \\
\hline $\mathrm{CV}(\%)$ & 12,39 & 13,66 & 0,99 & 1,62 & - \\
\hline
\end{tabular}

${ }^{(1)}$ As médias seguidas da mesma letra na coluna, não diferem entre si pelo Teste de Tukey ao nível de 5\% de probabilidade.

*Significativo em nível de 5\% de probabilidade; ns - não significativo. 
O uso do silício evitou perda de 2,02 a 2,11 g por massa de 100 grãos, enquanto nenhuma diferença foi observada para número de grãos/vagem e rendimento.

\section{CONCLUSÕES}

Uma aplicação de silício proporcionou proteção às plantas de amendoim reduzindo o número de adultos e ninfas do tripes de E. flavens e aumentou a produtividade da cultura em $31,30 \%$ de amendoim em casca e $28,85 \%$ em grãos.

\section{REFERÊNCIAS BIBLIOGRÁFICAS}

BASAGLI, M.A.B.; MORAES, J.C.; CARVALHO, G.A.; ECOLE, C.C.; GONÇALVES-GERVÁSIO, R.C.R. Effect of sodium silicate on the resistance of wheat plants to green-aphids Schizaphis graminum (Rond.) (Hemiptera: Aphididae). Neotropical Entomology, Londrina, v.32, n.3, p.659-663., 2003.

CHABOUSSOU, F. Plantas doentes pelo uso de agrotóxicos: a teoria da trofobiose. 2.ed. Porto Alegre: L\&PM, 1999. 272p.

COSTA, R.R.; MORAES, J.C. Resistência induzida em sorgo por silicato de sódio e infestação inicial pelo pulgão-verde Schizaphis graminum. Ecossistema, Espírito Santo do Pinhal, v.27, n.1/2, p.37-39, 2002.

COSTA, R.R.; MORAES, J.C.; ANTUNES, C.S. Resistência induzida em trigo ao pulgão Schizaphis graminum (Rondani, 1852) (Hemiptera: Aphididae) por silício e acibenzolar-s-methyl. Ciência e Agrotecnologia, Lavras, v.31, n.2, p.393-397, 2007.

DANNON, E.A.; WYDRA, K. Interaction between silicon amendment, bacterial wilt development and phenotype of Ralstonia solanacearum in tomato genotypes. Physiological and Molecular Plant Pathology, v.64, p.233-243, 2004.

DATNOFF, L.E.; RAID, R.N.; SNYDER, G.H.; JONES, D.B. Effect of calcium silicate on blast and brown spot intensities and yields of rice. Plant Disease, Saint Paul, v.75, n.7, p.729-732, 1991.

DÉLANO-FRIER, J.P.; MARTÍNEZ-GALLARDO, N.A.; DE LA VEGA, O.M.; SALAS-ARAIZA, M.D.; VARGAS, P.; BORODANENKO, A. The effect of exogenous jasmonic acid on induced resistance and productivity in amaranth (Amaranthus hypochondriacus) is influenced by environmental conditions. Journal of Chemical Ecology, New York, v.30, n.5, p.1001-1034, May 2004.

EMPRESA BRASILEIRA DE PESQUISA AGROPECUÁRIA. Sistema brasileiro de classificação de solos. Brasília, 1999. 412p.

EPSTEIN, E. A anomalia de silício em biologia vegetal. Proceedings of National Academy of United States of America, Washington, v.91, n.1, p.11-17, 1994.

EPSTEIN, E. Silicon in plants: facts vs concepts. In: DATNOFF, L.E.; SNYDER, G.H.; KORNDÖRFER, G.H. (Eds.). Silicon in agriculture. The Netherlands: Elsevier Science, 2001.

FAWE, A.; MENZIES, J.G.; CHERIF, M.; BÉLANGER, R.R. Silicon and disease resistance in dicotyledons. In: DATNOFF, L.E.; SNYDER, G.H.; KORNDÖRFER, G.H. (Eds.). Silicon in agriculture. The Netherlands: Elsevier Science, 2001.

FREDDI, O.S.; CAMPOS, A.R.; LEONEL, C.L.; FREDDI, T.S.; BARBOSA, G.F. Período de suscetibilidade do amendoinzeiro cv. Tégua ao tripes do prateamento e seu reflexo na produtividade. Acta Scientiarum Agronomy, Maringá, v.29, n.2, p.277-282, 2007.

GABRIEL, D.; NOVO, J.P.S.; GODOY, I.J. Efeito do controle químico na população de Enneothrips flavens Moul. e na produtividade de cultivares de amendoim Arachis hipogaea L. Arquivo Instituto Biológico, São Paulo, v.65, n.2, p.51-56, 1999.

GOMES, F.B.; MORAES, J.C.; SANTOS, C.D.; GOUSSAIN, M.M. Resistance induction in wheat plants by silicon and aphids. Scientia Agricola, Piracicaba, v.62, n.6, p.547-551, nov./dez. 2005.

GOUSSAIN, M.M.; MORAES, J.C.; CARVALHO, J.C.; NOGUEIRA, N.L. Efeito da aplicação de silício em plantas de milho no desenvolvimento biológico de lagarta-do-cartucho Spodoptera frugiperda (J. E. Smith) (Lepidoptera: Noctuidae). Neotropical Entomology, Londrina, v.31, n.2, p.305-310, 2002.

KIM, H.S.; HEINRICHS, E.A. Effects of silica level on whitebacked planthopper. International Rice Research Newsletter, v.7, n.17, 1982. 
KORNDÖRFER, G.A.; DATNOFF, L.E. Adubação com silício: uma alternativa no controle de doenças de canade-açúcar e do arroz. Informações Agronômicas, Piracicaba, n.70, p.1-5, jun. 1995.

\section{LASCA, D.H.C.; NEVES, G.S.; SANCHES, S.V. Extensão} do MIP amendoim em São Paulo. In: FERNANDES, O.A. (Ed.). Manejo integrado de pragas e nematóides. Jaboticabal: FUNEP, 1990. p.27-38

MARSCHNER, H. Mineral nutrition of higher plants. 2.ed. San Diego: Academic, 1988. 889p.

MARSCHNER, H. Mineral nutrition of higher plants. 2.ed. London: Academic, 1995. 889p.

MORAES, S.A.; GODOY, I.J.; PEDRO JÚNIOR, M.J.; MARTINS, A.L.M.; PEREIRA, J.C.V.N.A.; PEZZOPANE, J.R.M. Monitoramento da mancha preta associado a parâmetros climáticos para predizer a necessidade de controle químico em amendoim. Fitopatologia Brasileira, Brasília, v.22, p.419-426, 1997.

MORAES, J.C.; GOUSSAIN, M.M.; BASAGLI, M.A.B. Silicon influence on the tritrophic interaction: wheat plants, the greenbug Schizaphis graminum (Rondani) (Hemiptera: Aphididae), and its natural enemies,

Chrysoperla externa (Hagen) (Neuroptera: Chrysopidae) and Aphidius colemani Viereck (Hymenoptera: Aphidiidae). Neotropical Entomology, Vacaria, v.33, n.5, p.619-624, 2004.

NOJOSA, G.B.A.; RESENDE, M.L.V.; RESENDE, A.V. Uso de fosfitos e silicatos na indução de resistência. In:
CAVALCANTI, L.S. et al. (Eds.). Indução de resistência em plantas a patógenos e insetos. Piracicaba: FEALQ, 2006.

PEREIRA JUNIOR, P.; REZENDE, P.M.; MALFITANO, S.C.; LIMA, R.K.; CORRÊA, L.V.T.; CARVALHO, E.R. Efeito de doses de silício sobre a produtividade e características agronômicas da soja [Glycine max (L.) Merrill]. Ciência e Agrotecnologia, Lavras, v.34, n.4, p.908-913, jul./ago., 2010.

RAIJ, B.V.; CANTARELLA, H.; QUAGGIO, J.A.; FURLANI, A.M.C. Recomendações de adubação e calagem para o Estado de São Paulo. 2.ed. Campinas: Instituto Agronômico, 1996. (Boletim técnico, 100).

SAVANT, N.K.; SNYDER, G.H.; DATNOFF, L.E. Silicon management and sustainable rice production. Advances in Agronomy, San Diego, v.58, p.151-199, 1997.

SILVA, V.F.da; MORAES, J.C.; MELO, B.A. Influence of silicon on the development, productivity and infestation by insect pests in potato crops. Ciência e Agrotecnologia, Lavras, v.34, n.6, p.1465-1469, nov./ dez., 2010.

SUBRAMANIAN, S.; GOPALASWAMY, A. Effect of silicate materials on rice crop pests. International Rice Research Newsletter, v.13, p.32, 1988.

YOSHIDA, A.S.; OHNISHI, Y.; KITAGISHI, K. Histochemistry of silicon in rice plant. Soil Science and Plant Nutrition, v.8, p.107-111, 1962. 